\title{
Glioblastoma multiforme as a secondary malignancy following stereotactic radiosurgery of a meningioma: case report
}

\author{
Jason J. Labuschagne, MMED, ${ }^{1-3}$ and Dinoshan Chetty, MMED ${ }^{3}$ \\ 1Department of Neurosurgery, University of the Witwatersrand; '2Department of Paediatric Neurosurgery, Nelson Mandela \\ Children's Hospital; and ${ }^{3}$ Gamma Knife Centre, Milpark, Johannesburg, South Africa
}

\begin{abstract}
The documentation and exact incidence of stereotactic radiosurgery (SRS)-induced neoplasia is not well understood, with most literature restricted to single case reports and single-center retrospective reviews. The authors present a rare case of radiosurgery-induced glioblastoma multiforme (GBM) following radiosurgical treatment of a meningioma. A 74-year-old patient with a sporadic meningioma underwent radiosurgery following surgical removal of a WHO grade II meningioma. Eighteen months later she presented with seizures, and MRI revealed an intraaxial tumor, which was resected and proven to be a glioblastoma. As far as the authors are aware, this case represents the third case of GBM following SRS for a meningioma. This report serves to increase the awareness of this possible complication following SRS. The possibility of this rare complication should be explained to patients when obtaining their consent for radiosurgery.

https://thejns.org/doi/abs/10.3171/2019.3.FOCUS1948
\end{abstract}

KEYWORDS malignant transformation; glioblastoma; meningioma; radiosurgery

$\mathrm{T}$ HE indications for and use of radiotherapy in the management of benign and malignant intracranial neoplastic and nonneoplastic pathologies is increasing. The minimal upfront risks of focused radiotherapy are highly attractive-however, the potential long-term carcinogenic risk of secondary de novo malignant tumor induction or malignant conversion of a benign primary tumor needs to be considered. The concept of radiation oncogenesis is well established, and radiation-induced neoplasms after conventional fractioned radiotherapy are well documented ${ }^{67}$ The documentation of radiation-induced neoplasms following stereotactic radiosurgery (SRS), however, is not as well established, with very few cases reported in the literature. ${ }^{21,67} \mathrm{We}$ report a case of an SRS-induced glioblastoma multiforme (GBM) following treatment for a meningioma.

\section{Case Report}

A 74-year-old previously healthy woman with no significant prior history or familial history of cancer presented with progressive left-sided weakness. She was diagnosed with a $4.8 \times 3 \times 4.5-\mathrm{cm}$ parafalx meningioma (Fig. 1). Preoperative digital subtraction angiography revealed a patent sagittal sinus. Preoperative embolization was not feasible. A craniotomy was performed for removal of the lesion. All gross tumor other than that invading the sagittal sinus was removed. Histological investigation revealed an atypical meningioma (WHO grade II). SRS was offered for treatment of the remaining dural/intrasinus segment, and SRS-Gamma Knife (SRS-GK) was performed. The maximum and marginal doses were $14 \mathrm{~Gy}$ and $28 \mathrm{~Gy}$, respectively. A follow-up MRI study performed 6 months after the SRS was clear of recurrence. At 18 months after the surgery and SRS the patient presented with a seizure. Repeated MRI revealed a right-sided parietal lesion with inhomogeneous contrast enhancement, measuring $5 \times 5.2$ $\times 3.9 \mathrm{~cm}$. Figure 2 demonstrates the GK treatment plan overlaid on the MR image demonstrating the GBM. The lesion had arisen in the low-dose, peripheral region of the SRS field. A craniotomy was performed for resection of the lesion. Histology revealed a glioblastoma, with the tumor displaying high cellularity and focal necrosis. Immunohistochemical investigation yielded a positive response

ABBREVIATIONS GBM = glioblastoma multiforme; GK = Gamma Knife; MPNST = malignant peripheral nerve sheath tumor; NF2 = neurofibromatosis type 2; SRS = stereotactic radiosurgery; $V S=$ vestibular schwannoma.

SUBMITTED January 24, 2019. ACCEPTED March 18, 2019

INCLUDE WHEN CITING DOI: 10.3171/2019.3.FOCUS1948. 


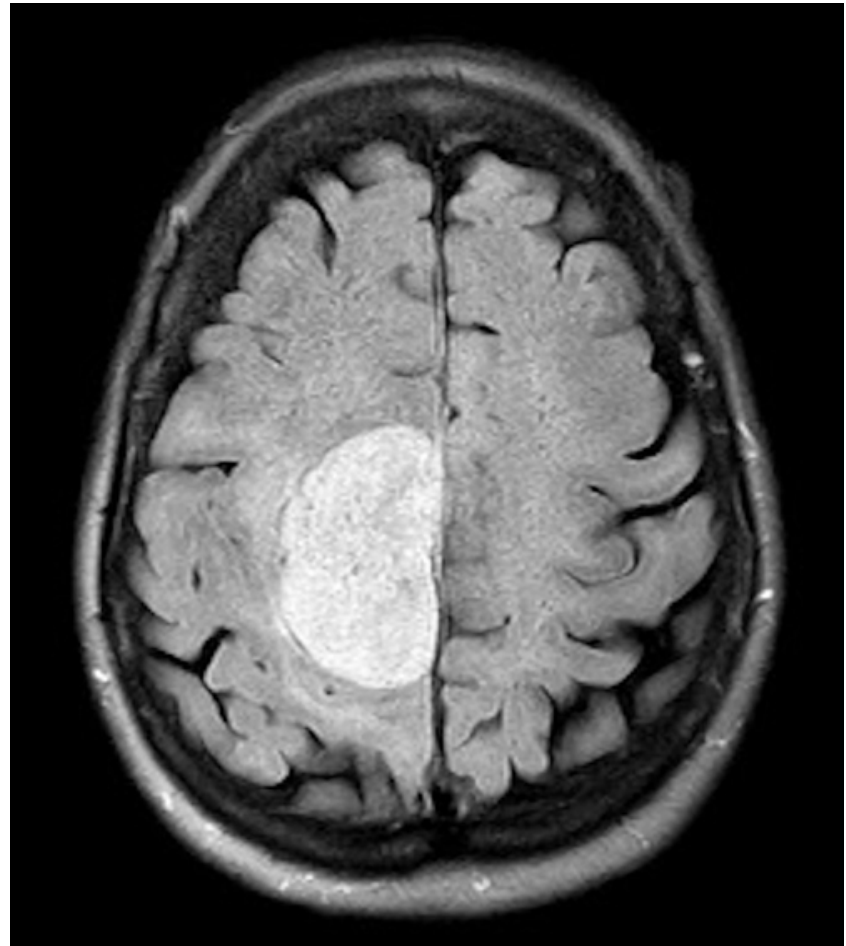

FIG. 1. Presurgical axial MR image showing the meningioma in our patient.

to anti-GFAP, and the Ki-67 showed a high proliferation rate $(>20 \%)$. As far as we are aware this is the 11th case of GBM following SRS and the third case following SRS for a meningioma.

\section{Methods}

We performed a detailed search of the PubMed/MEDLINE database, using the following key words: malignant transformation, radiation induced, radiation associated, stereotactic radiosurgery, gamma knife, cyber knife, secondary neoplasm, secondary tumor, and combinations thereof. There were no limitations on language or time of publication. We also manually reviewed all relevant citations for additional cases.

\section{Results}

We identified 16 reported cases of de novo secondary malignant tumor formation in patients with no genetic predisposition to neoplasia (Table 1), to which we added our present case. In addition, we identified an additional 5 cases of de novo secondary benign lesions (Table 2), and 17 cases of malignant progression/transformation in patients with no genetic predisposition to neoplasia (Table 3). An additional 3 cases of secondary malignant neoplasms developing following SRS in patients with an existing malignant CNS neoplasm were identified (Table 4).

In addition to this we identified 4 cases of de novo secondary malignant tumors and 9 cases of malignant progression of the primary lesion in patients with a genetic susceptibility to carcinogenesis (Tables 5 and 6 , respectively).

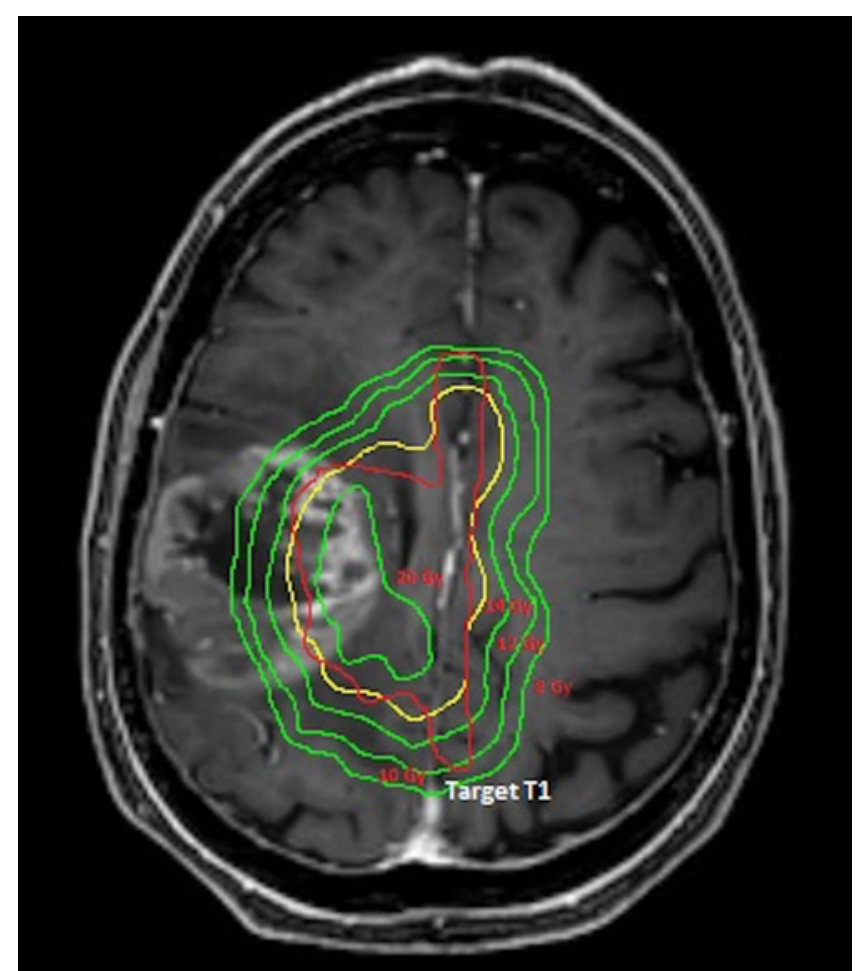

FIG. 2. Gamma Knife treatment plan superimposed on axial MR image demonstrating the GBM.

\section{Discussion}

The delayed risk of both benign and malignant neoplasm in tissue exposed to conventional radiation therapy is well known and has a cumulative risk of $1.3 \%$ at 10 years, and approximately $2 \%$ by 20 years posttreatment..$^{9,10}$ The risk of SRS-induced neoplasia is unfortunately far less understood. In a literature review Patel and Chiang ${ }^{43}$ estimated the risk of combined de novo tumor induction and malignant transformation to be $0.04 \%$ at 15 years, in contrast to the largest retrospective study to date, in which Wolf et al. ${ }^{65}$ reviewed the results from 5 SRS-GK centers and included 4905 patients. The cumulative incidence of SRS-associated malignancy in Wolf et al. was only $0.00045 \%$.

The criteria for radiation-induced neoplasia were established by Cahan et al. ${ }^{11}$ in 1948 , and are as follows: 1) the secondary tumor must appear within the irradiated field; 2) the secondary tumor must not be present before irradiation; 3) a sufficient latency period (usually 5 years) must elapse between the irradiation and the appearance of the tumor; 4) the patient must not have a genetic predisposition to a second malignancy; and 5) the histological findings must be distinct from those of the original irradiated lesion.

Adhering strictly to the original Cahan criteria eliminates a significant percentage of the reported cases of SRSinduced neoplasia. This arises for several reasons when treating with SRS: many cases do not have pre-SRS histological studies given that most patients are treated without a definite histological diagnosis; many of these patients do have a genetic predisposition toward neoplasia, in particular patients with neurofibromatosis type 2 (NF2); and a latency of 5 years may not be appropriate following SRS-in- 
TABLE 1. De novo secondary malignant tumors in patients with no genetic predisposition

\begin{tabular}{|c|c|c|c|c|c|c|}
\hline Authors \& Year & $\begin{array}{l}\text { Age (yrs), } \\
\text { Sex }\end{array}$ & Primary Lesion & Modality & Dose & Latency & Second Malignancy \\
\hline Yu et al., 2000 & $63, F$ & Meningioma & SRS-GK & $20 \mathrm{~Gy}$ & $7 \mathrm{yrs}$ & GBM \\
\hline Kaido et al., 2001 & $14, \mathrm{M}$ & AVM & SRS-GK & 20 Gy & $6.25 \mathrm{yrs}$ & GBM \\
\hline Shamisa et al., 2001 & $57, \mathrm{M}$ & VS & SRS-GK & $11 \mathrm{~Gy}$ & 7.5 yrs & GBM \\
\hline Salvati et al., 2003 & $66, \mathrm{~F}$ & Cavernous angioma & SRS-GK & $10 \mathrm{~Gy}$ & 13 yrs & GBM \\
\hline Muracciole et al., 2004 & $64, F$ & VS & SRS-GK & $13 \mathrm{~Gy}$ & 8.4 yrs & GBM \\
\hline Sanno et al., 2004 & $53, F$ & Meningioma & SRS-GK & $30 \mathrm{~Gy}$ & 4 yrs & Sarcoma \\
\hline Balasubramaniam et al., 2007 & $60, \mathrm{~F}$ & VS & SRT & Total dose 50 Gy & $5 \mathrm{yrs}$ & GBM \\
\hline Berman et al., 2007 & $34, \mathrm{~F}$ & AVM & SRS & 15 Gy & 9 yrs & GBM \\
\hline Rowe et al., $2007^{49}$ & $\mathrm{NR}, \mathrm{F}$ & Cavernous angioma & SRS-GK & $10 \mathrm{~Gy}$ & 8 yrs & AA \\
\hline Lee et al., 2012 & $47, \mathrm{~F}$ & Meningioma & SRS-GK & 16 Gy & $4.8 \mathrm{yrs}$ & GBM \\
\hline Sasagawa et al., 2013 & $24, \mathrm{~F}$ & PA & SRS-GK & 16 Gy & $15 \mathrm{yrs}$ & Sarcoma \\
\hline Starke et al., 2014 & $26, M$ & AVM & SRS-GK & $12 \mathrm{~Gy}$ & 25 yrs & AA \\
\hline Yoshida et al., 2014 & $4, \mathrm{~F}$ & AVM & SRS-GK & 16 Gy & $5.8 \mathrm{yrs}$ & GBM \\
\hline Xhumari et al., 2015 & $21, \mathrm{~F}$ & AVM & SRS-CK & $10 \mathrm{~Gy}$ & 6 yrs & GBM \\
\hline Kapurch et al., 2016 & $54, \mathrm{M}$ & VS & SRS-GK & $12.5 \mathrm{~Gy}$ & 3 yrs & Gliosarcoma \\
\hline Arán-Echabe et al., 2016 & $69, \mathrm{~F}$ & VS & SRS-GK & 13 Gy & 3.4 yrs & AA \\
\hline Present study & $74, \mathrm{~F}$ & Meningioma & SRS-GK & 14 Gy & $1.5 \mathrm{yrs}$ & GBM \\
\hline
\end{tabular}

$\mathrm{AA}=$ anaplastic astrocytoma; $\mathrm{AVM}=$ arteriovenous malformation; $\mathrm{CK}=$ CyberKnife; $\mathrm{PA}=$ pituitary adenoma; $\mathrm{SRT}$ = stereotactic radiotherapy.

duced neoplasms. ${ }^{29,66}$ There has been a proposal to modify the criteria of Cahan et al. ${ }^{11}$ to include cases with a shorter latency. ${ }^{13,39}$ For these reasons we have chosen to present all the cases described in the literature, with the caveat that they do not all meet the original Cahan criteria. We report the cases with a genetic predisposition separately from the remainder of the cases.

The risk of radiosurgery-induced tumor formation has generally been thought to be quite low for several reasons. 1) The irradiated volume is very small compared with traditional radiotherapy techniques. 2) The volumes and doses of radiation along the entry and exit pathways are small, and therefore the likelihood of secondary tumors would be diminished. ${ }^{28}$ 3) The high single doses delivered during SRS would preferentially lead to cytotoxicity over mutagenicity. ${ }^{43}$

This may be an oversimplification, however. In fact, basic science and clinical studies instead support a biphasic response to radiation carcinogenesis ${ }^{19}$ i.e., when cells are irradiated, the probability of malignancy increases with dose - with no dose too small to be causative ${ }^{29}$ - up to a dose of 3-10 Gy, followed by a subsequent increase in cell cytotoxicity and a fall in tumorigenicity. ${ }^{40}$ Importantly, the severity of the secondary tumor is not related to the dose of radiation..$^{38}$

The foregoing may account for the formation of secondary tumors in the low-dose peripheral regions of SRS fields. ${ }^{29,66}$ The presently reported case appears to support this. It may also explain why vestibular schwannomas (VSs), which are traditionally treated with lower SRS doses, are associated with greater rates of secondary neoplasms than would be expected..$^{43}$

\section{SRS-Induced Malignant Transformation in Nonpredisposed Patients}

We identified 17 reported cases of malignant progression of primary benign tumors exposed to SRS. All of these cases were VSs that de-differentiated into either a malignant peripheral nerve sheath tumor (MPNST, 12 cases), a triton (2 cases), an undifferentiated high-grade pleomorphic sarcoma ( 1 case), or a sarcoma ( 2 cases). The mean time to progression was 5.4 years. Not included in this case series are the results from the Mayo Clinic, ${ }^{46}$ which in a large retrospective study found 7 cases of malignant transformation in their patients with meningioma

TABLE 2. De novo secondary benign tumors in patients with no genetic predisposition

\begin{tabular}{ccccccc}
\hline Authors \& Year & Age (yrs), Sex & Primary Lesion & Modality & Dose & Latency & Second Malignancy \\
\hline Loeffler et al., 2003 & 41, M & PA & Proton beam & 87 Gy peak dose & 16 yrs & Meningioma \\
\hline Sheehan et al., 2006 & 53, M & PA & Proton beam & 104 Gy peak dose & 19 yrs & VS \\
\hline & 7, M & AVM & SRS-GK & 15 Gy & 15 yrs & Meningioma \\
\hline Copeland \& Link, 2013 & 60, M & AVM & SRS-GK & 25 Gy & 10 yrs & Meningioma \\
\hline
\end{tabular}

DAVF = dural arteriovenous fistula. 
TABLE 3. Malignant progression of primary benign tumor in patients with no genetic predisposition

\begin{tabular}{|c|c|c|c|c|c|c|}
\hline Authors \& Year & $\begin{array}{c}\text { Age (yrs) } \\
\text { Sex }\end{array}$ & $\begin{array}{l}\text { Primary } \\
\text { Lesion }\end{array}$ & Modality & Dose & Latency & $\begin{array}{c}\text { Second } \\
\text { Malignancy }\end{array}$ \\
\hline Comey et al., 1998 & $50, M$ & VS & SRS-GK & $14.4 \mathrm{~Gy}$ & $5 \mathrm{yrs}$ & Triton \\
\hline Hanabusa et al., 2001 & $51, \mathrm{~F}$ & VS & SRS-GK & $15 \mathrm{~Gy}$ & $6 \mathrm{mos}$ & MPNST \\
\hline Shin et al., 2002 & $26, F$ & VS & SRS-GK & $17 \mathrm{~Gy}$ & 6 yrs & MPNST \\
\hline Kubo et al., 2005 & $51, \mathrm{M}$ & VS & SRS-GK & $14 \mathrm{~Gy}$ & $8 \mathrm{mos}$ & MPNST \\
\hline Wilkinson et al., 2004 & $53, \mathrm{M}$ & VS & SRT & NR & 4 yrs & MPNST \\
\hline Muracciole et al., 2004 & $61, F$ & VS & SRS-GK & $10 \mathrm{~Gy}$ & 4 yrs & Triton \\
\hline Maire et al., 2006 & $45, \mathrm{~F}$ & VS & SRT & 1.8-Gy fractions, total dose $54 \mathrm{~Gy}$ & $8 \mathrm{yrs}$ & MPNST \\
\hline Chen et al., 2008 & $51, \mathrm{~F}$ & VS & SRS-GK & NR & $8 \mathrm{mos}$ & MPNST \\
\hline Van Rompaey et al., 2009 & $53, \mathrm{~F}$ & VS & SRS-GK & $12 \mathrm{~Gy}$ & $8 \mathrm{yrs}$ & MPNST \\
\hline Akamatsu et al., 2010 & $67, \mathrm{~F}$ & VS & SRS-GK & $12 \mathrm{~Gy}$ & $7.5 \mathrm{yrs}$ & MPNST \\
\hline Demetriades et al., 2010 & $27, \mathrm{M}$ & VS & SRS-GK & $15 \mathrm{~Gy}$ & $10 \mathrm{yrs}$ & MPNST \\
\hline Yang et al., 2010 & $74, \mathrm{M}$ & VS & SRS-GK & $12.5 \mathrm{~Gy}$ & $6 \mathrm{yrs}$ & Sarcoma \\
\hline Schmitt et al., 2011 & $51, \mathrm{M}$ & VS & SRS-GK & $12 \mathrm{~Gy}$ & $7.25 \mathrm{yrs}$ & UHGPS \\
\hline Puataweepong et al., 2012 & $34, \mathrm{~F}$ & VS & SRT & 30 Gy in 6 fractions & 6 yrs & MPNST \\
\hline Yanamadala et al., 2013 & $46, F$ & VS & SRS-GK & 14 Gy & $6 \mathrm{yrs}$ & MPNST \\
\hline Seferis et al., 2014 & $46, F$ & VS & SRS-GK & $12 \mathrm{~Gy}$ & 6 yrs & MPNST \\
\hline Se et al., 2017 & $49, \mathrm{~F}$ & VS & SRS-GK & $12.5 \mathrm{~Gy}$ & 6 yrs & Osteosarcoma \\
\hline
\end{tabular}

$\mathrm{NR}=$ not reported; UHGPS = undifferentiated high-grade pleomorphic sarcoma.

treated with SRS. In this series, meningioma patients were at the greatest risk of malignant transformation after SRS $(2.2 \%)$. The median time to malignant transformation in this group was 4.6 years.

\section{SRS-Induced Progression and New Malignancies in Patients With Known Genetic Mutations}

There appears to be a marked bias toward treating these patients, in particular patients with NF2 and Von HippelLindau disease, with SRS. ${ }^{50}$ This reflects the limitations of surgery and the more aggressive natural history of tumors in these patients.

The NF2 population poses a unique group. The initial mutation in NF2 results in an inherited loss of one NF2 gene on chromosome 22, resulting in the loss of an important tumor suppressor gene. According to the "two-hit" hypothesis of oncogenesis, ${ }^{45}$ radiation might induce a second "hit" and predispose these patients to secondary malignancies, both in the existing VS and the surrounding region. Our literature review identified 4 cases of de novo secondary malignant tumors and 9 cases of malignant progression of the primary lesion, all in patients with NF2 treated for VS (Tables 5 and 6). We identified 39 plus the present case of secondary tumor in nonpredisposed individuals. If you consider that the NF2 population probably accounts for only approximately $5 \%$ of the VS SRS-treated population, ${ }^{4}$ it appears that the NF2 population is overrepresented. Whether this reflects a true increase in SRS-induced malignancies is an open question. In a large survey of SRS in patients with NF2 who were treated for VS, Baser et al. ${ }^{6}$ estimated the incidence of MPNST in nonirradiated NF2 VSs to be less than $0.5 \%$, compared to a $6 \%$ incidence in NF2 VSs that had received SRS, suggesting a 12-fold increase. Likewise, Seferis et al..${ }^{55}$ using population incidences and reported cases, concluded that the risk of developing an MPNST following SRS was 9 to 14 times greater than in a nonirradiated VS population. In contrast to this are 4 large studies $26,34,48,59$ that demonstrated no increased risk of SRS-induced neoplasia. However, none of these aforementioned studies are large enough to detect very infrequent events such as malignant transformation.

According to Cahan' ${ }^{11}$ original criteria, these patients with NF2 should be excluded from the population of SRSinduced neoplasia, and certain authors do choose to do so. ${ }^{40}$ However, progression to MPNST is extremely rare, but not zero, and thus these patients should potentially still

TABLE 4. De novo secondary tumor in patients with a primary malignant tumor

\begin{tabular}{lcccccc}
\hline \multicolumn{1}{c}{ Authors \& Year } & $\begin{array}{c}\text { Age (yrs), } \\
\text { Sex }\end{array}$ & Primary Lesion & Modality & Dose & Latency & Second Malignancy \\
\hline Mclver \& Pollock, 2004 & $37, \mathrm{~F}$ & Metastatic melanoma & SRS-GK & 15 Gy & 5.3 yrs & AA \\
\hline Abedalthagafi \& Bakhshwin, 2012 & 43, F & Metastatic renal cell carcinoma & SRS-CK & NR & 4.5 yrs & GBM \\
\hline Nukaga et al., 2018 & $66, \mathrm{~F}$ & $\begin{array}{c}\text { Metastatic non-small cell lung } \\
\text { carcinoma }\end{array}$ & SRS-GK & NR & 5.7 yrs & GBM \\
\hline
\end{tabular}


TABLE 5. De novo secondary malignant tumors in patients with a genetic predisposition

\begin{tabular}{ccccccl}
\hline Authors \& Year & Age (yrs), Sex & Primary Lesion & Modality & Dose & Latency & \multicolumn{1}{c}{ Second Malignancy } \\
\hline Baser et al., 2000 & NR & VS & SRS-NR & NR & NR & Malignant meningioma \\
\hline Rowe et al., 200748 & NR & VS & SRS-NR & NR & NR & Malignant ependymoma \\
\hline Carlson et al., 2010 & 25, F & VS & SRS-GK & 14 Gy & 3 yrs & Glioblastoma \\
\hline
\end{tabular}

TABLE 6. Malignant progression of primary benign tumor in patients with a genetic predisposition

\begin{tabular}{lcccccc}
\hline \multicolumn{1}{c}{ Authors \& Year } & Age (yrs), Sex & Primary Lesion & Modality & Dose & Latency & Histological Findings \\
\hline Norén, 1998 & $18, \mathrm{~F}$ & VS & SRS-GK & $20 \mathrm{~Gy}$ & 5 yrs & Triton \\
\hline Thomsen et al., 2000 & $19, \mathrm{~F}$ & VS & SRS-GK & $12 \mathrm{~Gy}$ & 6 yrs & Meningiosarcoma \\
\hline Baser et al., 2000 & NR & VS & SRS-NR & NR & NR & MPNST \\
\hline & NR & VS & SRS-NR & NR & NR & MPNST \\
\hline Ho \& Kveton, 2002 & NR & VS & SRS-NR & NR & NR & MPNST \\
\hline Bari et al., 2002 & 14, F & VS & SRT & 18 Gy & 7 mos & NR (rapid growth) \\
\hline McEvoy \& Kitchen, 2003 & $22, \mathrm{~F}$ & VS & SRS-GK & $15 \mathrm{~Gy}$ & $3.5 \mathrm{yrs}$ & MPNST \\
\hline Tanbouzi Husseini et al., 2011 & $20, \mathrm{M}$ & VS & SRS-GK & $15 \mathrm{~Gy}$ & $2 \mathrm{yrs}$ & NR (rapid growth) \\
\hline
\end{tabular}

be included under the banner of radiation-induced neoplasia. ${ }^{4}$ In Maducdoc et al.'s ${ }^{32}$ review of the literature they identified 18 cases of primary malignant VS and 4 cases of "microsurgery-induced" VS transformation. These authors speculate that inflammation due to microsurgery or the effects of electrocoagulation may induce malignant transformation.

In addition to their possible genetic predisposition to transformation, VSs occur earlier in this group and they thus receive SRS at an earlier age. These patients therefore have a longer time to develop secondary malignancies because they accumulate radiation carcinogenic risks over a longer period of time. Several studies, in particular those involving breast carcinoma and radiation, have clearly demonstrated that young age at exposure is a particular risk factor for radiation-induced secondary cancer formation. ${ }^{19}$ The highest degree of caution should therefore be exercised in this group of patients undergoing SRS. ${ }^{4}$

Another important population group to consider is the patients with NF2 presenting with single or multiple meningiomas. In recent years SRS has been shown to be a safe and effective, definitive adjuvant treatment, not only for benign ${ }^{44}$ but also for WHO grade II and II meningiomas. ${ }^{18}$

The same concerns regarding an increased risk of malignant transformation and secondary de novo neoplasia for VS in patients with NF2 have been raised for SRS treatment of meningiomas in patients with NF2. ${ }^{20}$ The research, however, does not support an increased risk in these patients. In our review of the case reports, none of the meningiomas that were complicated by secondary malignancies were found in patients with NF, and no case reports of secondary degeneration in this group were identified. Additionally, 3 studies specifically looking at SRS-induced neoplasia in this group found no increased risk of this com- plication. ${ }^{8,30,48}$ Intuitively, NF2 cannot be protective against neoplasia; therefore the risk of malignant transformation in this group should be assumed to be at least that reported from the Mayo group in patients without NF2 (2.2\% at a mean follow-up duration of 4.9 years). ${ }^{46}$

The above evidence clearly indicates that there is a risk of malignant transformation following SRS, and the genetically predisposed group may be specifically at risk. This risk, although unknown, is thought to be very low. The number of reported cases of malignant transformation is already increasing and, as the numbers of cases treated with SRS increase and the latency period following SRS treatment lengthens, we can expect to see a further increase in these cases. ${ }^{31,55}$

\section{Conclusions}

The real risks of SRS-induced neoplasia remain very low, and in general should not deter one from offering radiotherapy to suitable patients. The risks are intuitively higher in the genetically predisposed group, but given the wide variance in reported risks in the literature, the true risks remain largely unknown in these patients. In particular, the patients with NF2 who have VS should be well counseled as to the risks of secondary neoplasia, and they should undergo long-term tumor surveillance given their unique predisposition.

\section{Acknowledgments}

We thank Dr. S. Taylor for the help in the preparation of this manuscript.

\section{References}

1. Abedalthagafi M, Bakhshwin A: Radiation-induced glioma 
following CyberKnife ${ }^{\circledR}$ treatment of metastatic renal cell carcinoma: a case report. J Med Case Reports 6:271, 2012

2. Akamatsu Y, Murakami K, Watanabe M, Jokura H, Tominaga T: Malignant peripheral nerve sheath tumor arising from benign vestibular schwannoma treated by gamma knife radiosurgery after two previous surgeries: a case report with surgical and pathological observations. World Neurosurg 73:751-754, 2010

3. Arán-Echabe E, Cascallar Caneda L, Lobato Busto R, Reyes Santías RM, Varela Pazo A, Gelabert-González M: [Highgrade glioma after stereotactic radiosurgery for vestibular schwannoma.] Neurocirugia (Astur) 27:33-37, 2016 (Spanish)

4. Balasubramaniam A, Shannon P, Hodaie M, Laperriere N, Michaels H, Guha A: Glioblastoma multiforme after stereotactic radiotherapy for acoustic neuroma: case report and review of the literature. Neuro Oncol 9:447-453, 2007

5. Bari ME, Forster DMC, Kemeny AA, Walton L, Hardy D, Anderson JR: Malignancy in a vestibular schwannoma. Report of a case with central neurofibromatosis, treated by both stereotactic radiosurgery and surgical excision, with a review of the literature. Br J Neurosurg 16:284-289, 2002

6. Baser ME, Evans DG, Jackler RK, Sujansky E, Rubenstein A: Neurofibromatosis 2, radiosurgery and malignant nervous system tumours. Br J Cancer 82:998, 2000

7. Berman EL, Eade TN, Brown D, Weaver M, Glass J, Zorman $\mathrm{G}$, et al: Radiation-induced tumor after stereotactic radiosurgery for an arteriovenous malformation: case report. Neurosurgery 61:E1099, 2007

8. Birckhead B, Sio TT, Pollock BE, Link MJ, Laack NN: Gamma Knife radiosurgery for neurofibromatosis type 2-associated meningiomas: a 22 -year patient series. J Neurooncol 130:553-560, 2016

9. Brada M, Rajan B, Traish D, Ashley S, Holmes-Sellors PJ, Nussey S, et al: The long-term efficacy of conservative surgery and radiotherapy in the control of pituitary adenomas. Clin Endocrinol (Oxf) 38:571-578, 1993

10. Breen P, Flickinger JC, Kondziolka D, Martinez AJ: Radiotherapy for nonfunctional pituitary adenoma: analysis of long-term tumor control. J Neurosurg 89:933-938, 1998

11. Cahan WG, Woodard HQ, Higinbotham NL, Stewart FW, Coley BL: Sarcoma arising in irradiated bone; report of 11 cases. Cancer 1:3-29, 1948

12. Carlson ML, Babovic-Vuksanovic D, Messiaen L, Scheithauer BW, Neff BA, Link MJ: Radiation-induced rhabdomyosarcoma of the brainstem in a patient with neurofibromatosis type 2. J Neurosurg 112:81-87, 2010 (Erratum in J Neurosurg 112:209, 2010)

13. Carlson ML, Glasgow AE, Jacob JT, Habermann EB, Link MJ: The short-term and intermediate-term risk of second neoplasms after diagnosis and treatment of unilateral vestibular schwannoma: analysis of 9460 cases. Int J Radiat Oncol Biol Phys 95:1149-1157, 2016

14. Chen L, Mao Y, Chen H, Zhou LF: Diagnosis and management of intracranial malignant peripheral nerve sheath tumors. Neurosurgery 62:825-832, 2008

15. Comey CH, McLaughlin MR, Jho HD, Martinez AJ, Lunsford LD: Death from a malignant cerebellopontine angle triton tumor despite stereotactic radiosurgery. Case report. J Neurosurg 89:653-658, 1998

16. Copeland WR, Link MJ: A radiation-induced meningioma "cures" a complex dural arteriovenous fistula. J Neurol Surg A Cent Eur Neurosurg 74 (Suppl 1):e215-e220, 2013

17. Demetriades AK, Saunders N, Rose P, Fisher C, Rowe J, Tranter R, et al: Malignant transformation of acoustic neuroma/vestibular schwannoma 10 years after gamma knife stereotactic radiosurgery. Skull Base 20:381-387, 2010

18. Ding D, Starke RM, Hantzmon J, Yen CP, Williams BJ, Sheehan JP: The role of radiosurgery in the management of
WHO Grade II and III intracranial meningiomas. Neurosurg Focus 35(6):E16, 2013

19. Epstein R, Hanham I, Dale R: Radiotherapy-induced second cancers: are we doing enough to protect young patients? Eur J Cancer 33:526-530, 1997

20. Evans DGR, Birch JM, Ramsden RT, Sharif S, Baser ME: Malignant transformation and new primary tumours after therapeutic radiation for benign disease: substantial risks in certain tumour prone syndromes. J Med Genet 43:289-294, 2006

21. Ganz JC: Gamma knife radiosurgery and its possible relationship to malignancy: a review. J Neurosurg 97 (5 Suppl):644-652, 2002

22. Hanabusa K, Morikawa A, Murata T, Taki W: Acoustic neuroma with malignant transformation. Case report. J Neurosurg 95:518-521, 2001

23. Ho SY, Kveton JF: Rapid growth of acoustic neuromas after stereotactic radiotherapy in type 2 neurofibromatosis. Ear Nose Throat J 81:831-833, 2002

24. Kaido T, Hoshida T, Uranishi R, Akita N, Kotani A, Nishi N, et al: Radiosurgery-induced brain tumor. Case report. J Neurosurg 95:710-713, 2001

25. Kapurch JR, Jacob JT, Carlson ML, Atkinson JL, Raghunathan A, Link MJ: Temporal lobe gliosarcoma after Gamma Knife radiosurgery for vestibular schwannoma. Otol Neurotol 37:1143-1147, 2016

26. Kida Y, Kobayashi T, Tanaka T, Mori Y: Radiosurgery for bilateral neurinomas associated with neurofibromatosis type 2. Surg Neurol 53:383-390, 2000

27. Kubo O, Chernov M, Izawa M, Hayashi M, Muragaki Y, Maruyama T, et al: Malignant progression of benign brain tumors after gamma knife radiosurgery: is it really caused by irradiation? Minim Invasive Neurosurg 48:334-339, 2005

28. Larson DA, Flickinger JC, Loeffler JS: The radiobiology of radiosurgery. Int J Radiat Oncol Biol Phys 25:557-561, 1993

29. Lee HS, Kim JH, Lee JI: Glioblastoma following radiosurgery for meningioma. J Korean Neurosurg Soc 51:98-101, 2012

30. Liu A, Kuhn EN, Lucas JT Jr, Laxton AW, Tatter SB, Chan MD: Gamma Knife radiosurgery for meningiomas in patients with neurofibromatosis Type 2. J Neurosurg 122:536-542, 2015

31. Loeffler JS, Niemierko A, Chapman PH: Second tumors after radiosurgery: tip of the iceberg or a bump in the road? Neurosurgery 52:1436-1442, 2003

32. Maducdoc MM, Ghavami Y, Linskey ME, Djalilian HR: Evaluation of reported malignant transformation of vestibular schwannoma: de novo and after stereotactic radiosurgery or surgery. Otol Neurotol 36:1301-1308, 2015

33. Maire JP, Huchet A, Milbeo Y, Darrouzet V, Causse N, Célérier D, et al: Twenty years' experience in the treatment of acoustic neuromas with fractionated radiotherapy: a review of 45 cases. Int J Radiat Oncol Biol Phys 66:170-178, 2006

34. Mathieu D, Kondziolka D, Flickinger JC, Niranjan A, Williamson R, Martin JJ, et al: Stereotactic radiosurgery for vestibular schwannomas in patients with neurofibromatosis type 2: an analysis of tumor control, complications, and hearing preservation rates. Neurosurgery 60:460-470, 2007

35. McEvoy AW, Kitchen ND: Rapid enlargement of a vestibular schwannoma following gamma knife treatment. Minim Invasive Neurosurg 46:254-256, 2003

36. McIver JI, Pollock BE: Radiation-induced tumor after stereotactic radiosurgery and whole brain radiotherapy: case report and literature review. J Neurooncol 66:301-305, 2004

37. Muracciole X, Cowen D, Régis J: [Radiosurgery and brain radio-induced carcinogenesis: update.] Neurochirurgie 50:414-420, 2004 (French)

38. Muracciole X, Régis J: Radiosurgery and carcinogenesis risk. Prog Neurol Surg 21:207-213, 2008 
39. Murray EM, Werner D, Greeff EA, Taylor DA: Postradiation sarcomas: 20 cases and a literature review. Int J Radiat Oncol Biol Phys 45:951-961, 1999

40. Niranjan A, Kondziolka D, Lunsford LD: Neoplastic transformation after radiosurgery or radiotherapy: risk and realities. Otolaryngol Clin North Am 42:717-729, 2009

41. Norén G: Long-term complications following gamma knife radiosurgery of vestibular schwannomas. Stereotact Funct Neurosurg 70 (Suppl 1):65-73, 1998

42. Nukaga S, Naoki K, Yasuda H, Kawada I, Ohara K, Soejima $\mathrm{K}$, et al: Secondary brain neoplasm after stereotactic radiosurgery in patients with metastatic non-small cell lung cancer. Intern Med 57:2383-2387, 2018

43. Patel TR, Chiang VLS: Secondary neoplasms after stereotactic radiosurgery. World Neurosurg 81:594-599, 2014

44. Pinzi V, Biagioli E, Roberto A, Galli F, Rizzi M, Chiappa $\mathrm{F}$, et al: Radiosurgery for intracranial meningiomas: a systematic review and meta-analysis. Crit Rev Oncol Hematol 113:122-134, 2017

45. Plowman PN, Evans DGR: Stereotactic radiosurgery XI. Acoustic neuroma therapy and radiation oncogenesis. Br J Neurosurg 14:93-95, 2000

46. Pollock BE, Link MJ, Stafford SL, Parney IF, Garces YI, Foote RL: The risk of radiation-induced tumors or malignant transformation after single-fraction intracranial radiosurgery: results based on a 25-year experience. Int J Radiat Oncol Biol Phys 97:919-923, 2017

47. Puataweepong P, Janwityanujit T, Larbcharoensub N, Dhanachai M: Radiation-induced peripheral malignant nerve sheath tumor arising from vestibular schwannoma after linac-based stereotactic radiation therapy: a case report and review of literatures. Case Rep Med 2012:648191, 2012

48. Rowe J, Grainger A, Walton L, Radatz M, Kemeny A: Safety of radiosurgery applied to conditions with abnormal tumor suppressor genes. Neurosurgery 60:860-864, 2007

49. Rowe J, Grainger A, Walton L, Silcocks P, Radatz M, Kemeny A: Risk of malignancy after gamma knife stereotactic radiosurgery. Neurosurgery 60:60-66, 2007

50. Salvati M, Frati A, Russo N, Caroli E, Polli FM, Minniti G, et al: Radiation-induced gliomas: report of 10 cases and review of the literature. Surg Neurol 60:60-67, 2003

51. Sanno N, Hayashi S, Shimura T, Maeda S, Teramoto A: Intracranial osteosarcoma after radiosurgery-case report. Neurol Med Chir (Tokyo) 44:29-32, 2004

52. Sasagawa Y, Tachibana O, Iizuka H: Undifferentiated sarcoma of the cavernous sinus after gamma knife radiosurgery for pituitary adenoma. J Clin Neurosci 20:1152-1154, 2013

53. Schmitt WR, Carlson ML, Giannini C, Driscoll CLW, Link MJ: Radiation-induced sarcoma in a large vestibular schwannoma following stereotactic radiosurgery: case report. Neurosurgery 68:E840-E846, 2011

54. Se YB, Kim DG, Park SH, Chung HT: Radiation-induced osteosarcoma after Gamma Knife surgery for vestibular schwannoma: a case report and literature review. Acta Neurochir (Wien) 159:385-391, 2017

55. Seferis C, Torrens M, Paraskevopoulou C, Psichidis G: Malignant transformation in vestibular schwannoma: report of a single case, literature search, and debate. J Neurosurg 121 (Suppl):160-166, 2014

56. Shamisa A, Bance M, Nag S, Tator C, Wong S, Norén G, et al: Glioblastoma multiforme occurring in a patient treated with gamma knife surgery. Case report and review of the literature. J Neurosurg 94:816-821, 2001

57. Sheehan J, Yen CP, Steiner L: Gamma knife surgery-induced meningioma. Report of two cases and review of the literature. J Neurosurg 105:325-329, 2006

58. Shin M, Ueki K, Kurita H, Kirino T: Malignant transformation of a vestibular schwannoma after gamma knife radiosurgery. Lancet 360:309-310, 2002
59. Spatola G, Carron R, Delsanti C, Thomassin JM, Roche PH, Régis J: Long-term results of Gamma-knife stereotactic radiosurgery for vestibular schwannomas in patients with type 2 neurofibromatosis. Neurochirurgie 64:355-363, 2018

60. Starke RM, Yen CP, Chen CJ, Ding D, Mohila CA, Jensen ME, et al: An updated assessment of the risk of radiationinduced neoplasia after radiosurgery of arteriovenous malformations. World Neurosurg 82:395-401, 2014

61. Tanbouzi Husseini S, Piccirillo E, Taibah A, Paties CT, Rizzoli R, Sanna M: Malignancy in vestibular schwannoma after stereotactic radiotherapy: a case report and review of the literature. Laryngoscope 121:923-928, 2011

62. Thomsen J, Mirz F, Wetke R, Astrup J, Bojsen-Møller M, Nielsen E: Intracranial sarcoma in a patient with neurofibromatosis type 2 treated with gamma knife radiosurgery for vestibular schwannoma. Am J Otol 21:364-370, 2000

63. Van Rompaey K, Michotte A, Ampe B, Moens M, Ates R, Chaskis C, et al: Malignant transformation of a vestibular schwannoma after radiosurgery. Surg Neurol 71:145, 2009 (Poster)

64. Wilkinson JS, Reid H, Armstrong GR: Malignant transformation of a recurrent vestibular schwannoma. J Clin Pathol 57:109-110, 2004

65. Wolf A, Naylor K, Tam M, Habib A, Novotny J, Liscak R, et al: Risk of radiation-associated intracranial malignant after stereotactic radiosurgery: a retrospective, multicenter, cohort study. Lancet 20:159-164, 2019

66. Xhumari A, Rroji A, Enesi E, Bushati T, Sallabanda Diaz K, Petrela M: Glioblastoma after AVM radiosurgery. Case report and review of the literature. Acta Neurochir (Wien) 157:889-895, 2015

67. Yamanaka R, Hayano A, Kanayama T: Radiation-induced gliomas: a comprehensive review and meta-analysis. Neurosurg Rev 41:719-731, 2018

68. Yanamadala V, Williamson RW, Fusco DJ, Eschbacher J, Weisskopf P, Porter RW: Malignant transformation of a vestibular schwannoma after gamma knife radiosurgery. World Neurosurg 79:593.e1-593.e8, 2013

69. Yang T, Rockhill J, Born DE, Sekhar LN: A case of highgrade undifferentiated sarcoma after surgical resection and stereotactic radiosurgery of a vestibular schwannoma. Skull Base 20:179-183, 2010

70. Yoshida K, Ichikawa T, Kurozumi K, Yanai H, Onoda K, Date I: Fatal glioblastoma after Gamma Knife radiosurgery for arteriovenous malformation in a child. J Clin Neurosci 21:1453-1455, 2014

71. Yu JS, Yong WH, Wilson D, Black KL: Glioblastoma induction after radiosurgery for meningioma. Lancet 356:15761577,2000

\section{Disclosures}

The authors report no conflict of interest concerning the materials or methods used in this study or the findings specified in this paper.

\section{Author Contributions}

Conception and design: Labuschagne. Acquisition of data: Labuschagne. Analysis and interpretation of data: Chetty. Drafting the article: Labuschagne. Critically revising the article: Chetty. Reviewed submitted version of manuscript: Labuschagne.

\section{Correspondence}

Jason J. Labuschagne: Nelson Mandela Children's Hospital, Johannesburg, South Africa. jason.labuschagne@nmch.org.za. 